\title{
Sidelobe level minimization for uniform circular smart antenna array using cultural algorithm
}

\author{
Asma Issa Mohsin', Asaad S. Daghal' ${ }^{2}$, Adheed Hasan Sallomi ${ }^{3}$ \\ ${ }^{1}$ Ministry of Oil, Baghdad, Iraq \\ ${ }^{1,2} \mathrm{Al}$-Furat Al-Awsat Technical University, Kufa, Iraq \\ ${ }^{3}$ Faculty of Engineering, Al-Mustansiriyah University, Baghdad, Iraq
}

\begin{tabular}{|c|c|}
\hline Article Info & ABSTRACT \\
\hline Article history: & \multirow{9}{*}{$\begin{array}{l}\text { Cultural algorithm (CA) is a new evolutionary program inspired by sociology } \\
\text { and archaeology theories that assisting formulating cultural evaluation. Its } \\
\text { use to solve optimization problems. This paper analyzed the beamforming of } \\
\text { a uniform circular antenna array (UCAA) via using the CA algorithm. The } \\
\text { sidelobe level (SLL) is minimized by adjusting the appropriate weight for } \\
\text { each element. In addition, the optimal beam pattern is achieved by using CA } \\
\text { for UCAA, which means that the main beam is steering to the desired user, } \\
\text { while the nulls represent the interference signals. The excitation amplitude is } \\
\text { supposed to be constant while the elements are assumed isotropic. The } \\
\text { circular array number elements and the interspacing distance between them } \\
\text { are setting as optimization parameters. The simulation results show that the } \\
\text { CA rationally reacts to the changing environments, and it is valuable for SLL } \\
\text { reduction. A - } 25 \mathrm{~dB} \text { of relative SLL is achieved under beam scanning }\left(0^{\circ}\right) \\
\text { and }\left(15^{\circ}\right) \text {, respectively. }\end{array}$} \\
\hline Received Apr 13, 2021 & \\
\hline Revised Sep 12, 2021 & \\
\hline Accepted Sep 16, 2021 & \\
\hline Keywords: & \\
\hline Beamforming & \\
\hline Circular array & \\
\hline Cultural algorithm & \\
\hline Smart antenna & \\
\hline
\end{tabular}

This is an open access article under the CC BY-SA license.

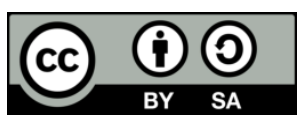

Corresponding Author:

Asaad S. Daghal

Engineering Technical College

Al-Furat Al-Awsat Technical University

Kufa, Iraq

Email: ad466kent@atu.edu.iq

\section{INTRODUCTION}

The statistics confirm the upward trend of using mobile wireless communication services around the world and it will increase exponentially in the upcoming years [1]. Studies indicate that data traffic has increased substantially due to the internet of things (IoT) applications and has become heavily dependent on wireless mobile communication service companies. All this is in light of the limited bandwidth like any other resources in nature [2]-[6]. Researchers have tended to solve the limited frequency spectrum by using different techniques to improve and enhance the data transmission, as well as to reduce energy consumption [7]-[9]. Smart antennas are considered one of the most promising technologies to handle these problems, where it's simply produced by attaching an ordinary antenna with certain algorithms to steer the main radiation pattern into the desired users while reducing the energy consumed by minimizing the sidelobes level (SLL) [10], [11]. This can be achieved through direct beamforming [12]-[23].

In [24], a space timing with multiple antennas at the base station has been constructed and analyzed through the utilized realistic processing method of interference and channel models. In [25], a multiple signal classification (MUSIC) algorithm has used to obtain the beamforming, where the deep nulls and the mean beam were considered only in the direction of signal interfering. In [26], three techniques, grey wolf optimization, least mean square, and genetic algorithm, were used to reduced SLL and increased directivity. 
A cultural algorithm (CA) is a cultural-social algorithm, which similar to a genetic algorithm. It is used instead of the biological integration optimization method. It was modeled by [27]. However, CA is used in this article to minimize the SSL. The paper contributions are listed below:

- The directivity is linked directly with inter-element spacing means when antenna spacing gets larger we obtain narrower beam width and higher directivity and it results in a more accurate beam pattern.

- The beam-width is also related to antenna elements number in a backward manner. Therefore, a better directivity has gained through the increase of antenna elements number in the UCA that give narrower beam-width.

The other section of this article is organized as follows: Section 2 describes a culture algorithm where its implementation steps are debated. Section 3 illustrates a configuration of a uniform circular antenna array (UCAA), where the array factor equations are analyzed. In Section 4, several cases for uniform circular array analysis that optimized with the $\mathrm{CA}$ algorithm with changing the inter-spacing between elements and number of elements are studied. Moreover, the array patterns are demonstrated in the same section, while the conclusions are clarified in section five.

\section{CULTURAL ALGORITHM PROCESS}

The CA process can be summarized as follows [28]-[32]:

- The population is established as a collection of individuals (probable solution). Every individual can be described by two terms, the first one is a set of traits or behavior, and the second term is the Mappa or generalized description of their experiences. Traits can be lost or added to the population. It can also be changed and exchanged between individuals. In every generation, the set of individuals are qualified in terms of currently usable traits.

- A fitness function is used to evaluate the performance of each individual through a set of chosen parameters.

- A generalized map of the experience is produced from every individual during a time, which is defined as outlining. A dominant belief is launched upon the most general belief that generated Mappa.

- The adjusted belief space has defined a group of present acceptable Mappa collections at a given time level. The rejected Mappa can be forced or not at the population level. The individual processing of the associated beliefs is not allowed in the group of the next generations when the rejected Mappa is forced; while it can be, resurface in the next populations when the group does not impose the rejection of Mappa.

- Several things can be changed through the belief space, such as the effectiveness of individuals in the population space, impose the rejected Mappa, and change the set of acceptable traits. Thereafter, a new population is generated by population space via selecting individuals to be parents for the next generation. It is used to promote a new population through the enforcement changes of different factors. In this way, the processing is integrated with parallel due to the possibility that there can be many groups placing in the belief space. Every boosted through a subcollection of the present population can utilize a function or fraction of the solving environment problem. The outlining, merging and pruning processes together with the acceptance and combination tasks is defined how the beliefs space would be searched in parallel by individuals in the populations. Figure 1 simply illustrates the CA process.

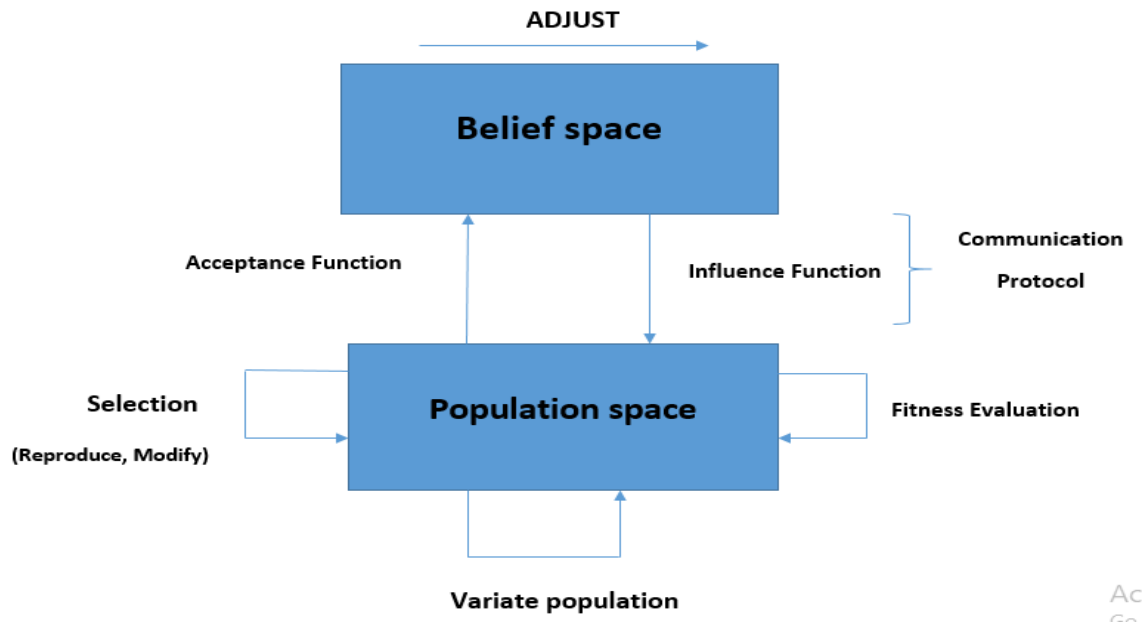

Figure 1. Cultural algorithm flow chart 


\section{CONFIGURATION OF UNIFORM CIRCULAR ANTENNA ARRAY}

The elements are set in a circular ring in the uniform circular antenna array, where it has equally spaced for $\mathrm{N}$ number of it. In the present wireless communication systems, a circular array has been suggested in smart antenna applications [33]-[43]. It has the capability of scanning through 360 degrees azimuthally. Figure 2 shows a geometry of a uniform circular antenna of N-elements.

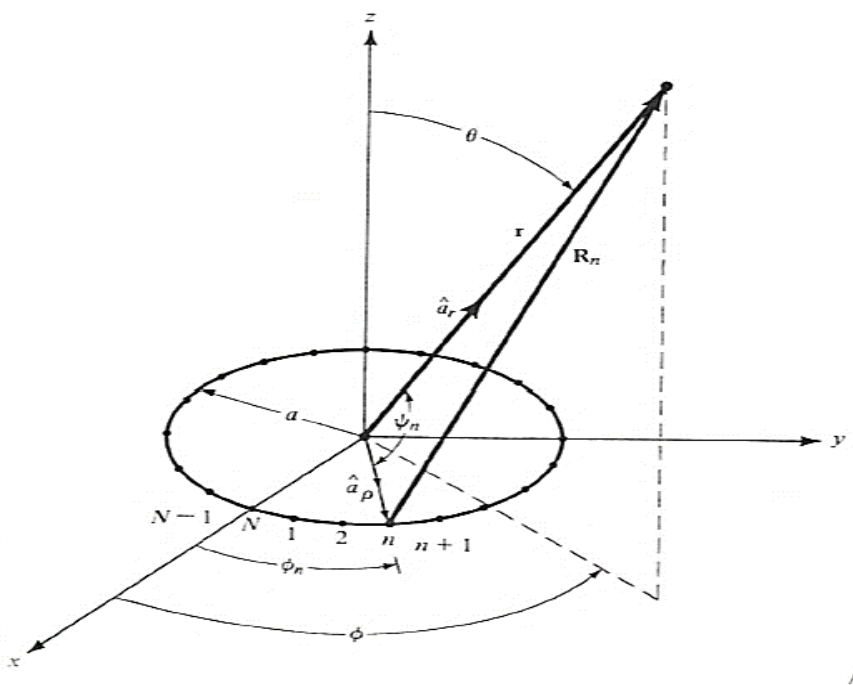

Figure 2. Geometry of UCAA

The circular array has consisted of $\mathrm{N}$-isotropic elements, which are equally spaced through the $\mathrm{x}-\mathrm{y}$ plane over the circular ring of radius $\alpha$. The array factor (AF) of UCAA is given by [10]:

$$
A F(\Theta, \phi, d)=\sum_{n=1}^{N} I_{n} e^{j\left[K \alpha \sin \Theta \cos \left(\phi-\phi_{n}\right)+\alpha_{n}\right]}
$$

where $I_{n}$ is the value of amplitude excitation of $n^{\text {th }}$ element, $\alpha_{n}$ is the $n^{\text {th }}$ element excitation phase and $\phi_{n}$ is the $n^{\text {th }}$ element angular position in the x-y plane, and $d$ is the arc distance between every two elements. The main beam in the $\left(\Theta_{0}, \phi_{0}\right)$ direction indicates to the peak of the phase excitation of the $n^{\text {th }}$ element, which is expressed as:

$$
\alpha_{n}=-k \sin \theta_{0} \cos \left(\phi_{0}-\phi_{n}\right)
$$

So, the $A F$ is given by:

$$
A F(\Theta, \phi, d)=\sum_{n=1}^{N} I_{n} e^{j k \alpha\left[\sin \Theta \cos \left(\phi-\phi_{n}\right)-\sin \Theta_{0} \cos \left(\phi_{0}-\phi_{n}\right)\right]}
$$

And it can be simplified to:

$$
A F(\Theta, \phi, d)=\sum_{n=1}^{N} I_{n} e^{j k \alpha\left[\cos -\cos \left(\varphi_{0}\right)\right]}
$$

The fitness function of UCAA can be written as:

$$
\text { Fitness }=\min \left(\max \left(\left[20 \log \left(\frac{A F(\theta, \phi, d)_{\max }}{A F(\theta, \phi, d)}\right)\right]\right)\right)
$$

In this case study, the number of elements and the separation distance between them is taken as optimization parameters.

\section{RESULTS AND DISCUSSION}

The CA optimization method is applied to decrease the SLL in which the main beam is steered at different angles. The performance of the system is analyzed through a MATLAB simulation tool. A relation 
between the phase angle and SLL of different elements has been taking into account. The main paper simulation parameters are listed in Table 1.

In this paper, the number of circular array elements is setting to 15 and 20, respectively. Besides, the spacing between elements is setting by $0.5 \lambda$ and $0.75 \lambda$, respectively. Tables 2 and 3 shows the effect of antenna parameters when the inter-element spacing and the number of elements are varied. From Table 2, it is noticed that the increased number of array elements results in raising the maximum array output, which causes a sharper beam with more directivity. Though it is caused the improvement, it brings more SSL. Table 3 recognized that the increase of inter-element spacing results in less maximum array output, which means less directivity.

For different case studies. Firstly, fifteen elements of UCAA with $0.5 \lambda$ interspacing amongst elements have been studied. Figures 3(a) and (b) shows the plots of the effective parameters accomplished by applying the CA algorithm. Figure 3(a) shows that the maximum array output is close to one. Also, from Figure 3(b), the normalized value of maximum AF output and maximum value of sidelobe level is equal to -0.0022 and -10.44 , respectively.

Secondly, a 15 -element of UCAA with $0.75 \lambda$ interspacing between elements have been taken. From Figure 4(a), it is clear that the maximum array output is 0.922 that is close to the desired output. From Figure 4(b), it can recognize that the maximum AF output is -0.0319 , while the maximum sidelobe level is -10.44. As a comparison between Figure 3(a) and Figure 4(a), it can recognize that the maximum array output is decreased from 0.997 to 0.922 when the inter-element spacing increased from $0.5 \lambda$ to $0.75 \lambda$.

Thirdly, a 20 -element of UCAA with $0.5 \lambda$ interspacing between elements were examined. From Figure 5(a), it is noticed that the maximum array output is 0.99 . Also, in Figure 5(b), the normalized value of maximum AF output is equal to 0 and the maximum value of sidelobe level equal to -10.44 . Finally, a $0.75 \lambda$ interspacing of twenty elements of a UCAA has been considered. From Figure 6(a), it is clear that the maximum array output is 1.002 which is more than the maximum array output with the same number of antenna elements with $0.5 \lambda$ inter-element spacing. In Figure 6(b), the normalized value of maximum AF output equal to -0.012 , and the maximum value of sidelobe level equal to -10.45 . As a comparison between Figure 5(b) and Figure 6(b), it can realize that the maximum sidelobe level is increased from -10.44 to -10.45 when the inter-element spacing increased from $0.5 \lambda$ to $0.75 \lambda$.

Table 1. Simulation parameters

\begin{tabular}{ll}
\hline \multicolumn{1}{c}{ Parameter } & Description \\
\hline Direction of arrival (DOA) & $\mathrm{DOA}=40$ \\
Direction of interference & $\mathrm{DOA}=0$ \\
No 0 of iteration & 250 \\
Element spacing & $0.5 \lambda, 0.75 \lambda$ \\
\hline
\end{tabular}

Table 2. Results based on number of elements

\begin{tabular}{cccc}
\hline $\begin{array}{c}\text { Number of } \\
\text { elements }\end{array}$ & $\begin{array}{c}\text { Peak of array } \\
\text { factor }\end{array}$ & $\begin{array}{c}\text { Max } \\
\text { SLL }\end{array}$ & $\begin{array}{c}\text { Max array } \\
\text { output }\end{array}$ \\
\hline 15 & -0.014 & -10.44 & 0.96 \\
20 & -0.014 & -10.46 & 0.994 \\
\hline
\end{tabular}

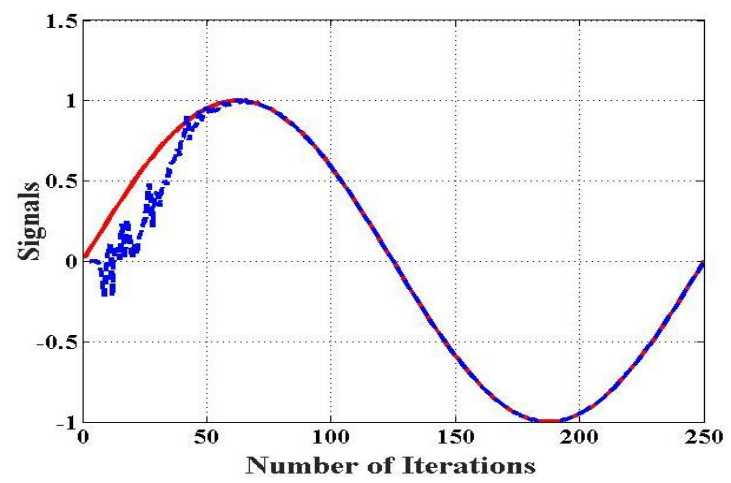

(a)
Table 3. Results based on inter-spacing distance

\begin{tabular}{cccc}
\hline $\begin{array}{c}\text { Element spacing } \\
\text { in } \lambda\end{array}$ & $\begin{array}{c}\text { Peak of array } \\
\text { factor }\end{array}$ & $\begin{array}{c}\text { Max } \\
\text { SLL }\end{array}$ & $\begin{array}{c}\text { Max array } \\
\text { output }\end{array}$ \\
\hline 0.5 & -0.01 & -10.44 & 1.003 \\
0.75 & -0.018 & -9.72 & 0.98 \\
\hline
\end{tabular}

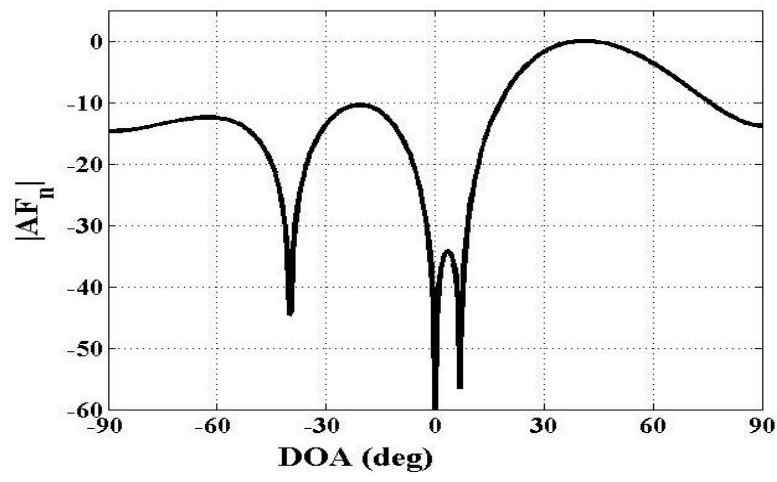

(b)

Figure 3. (a) max. Array o/p N=15, $\lambda=0.5$ and (b) max. $\mathrm{SLL}$, main lobe for $\mathrm{N}=15, \lambda=0.5$ 


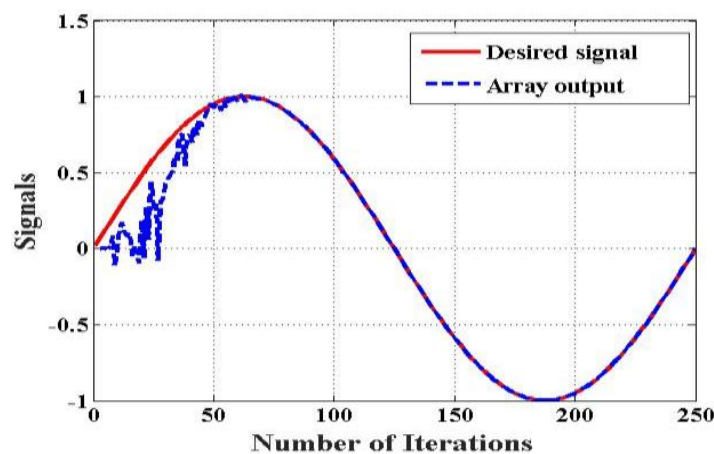

(a)

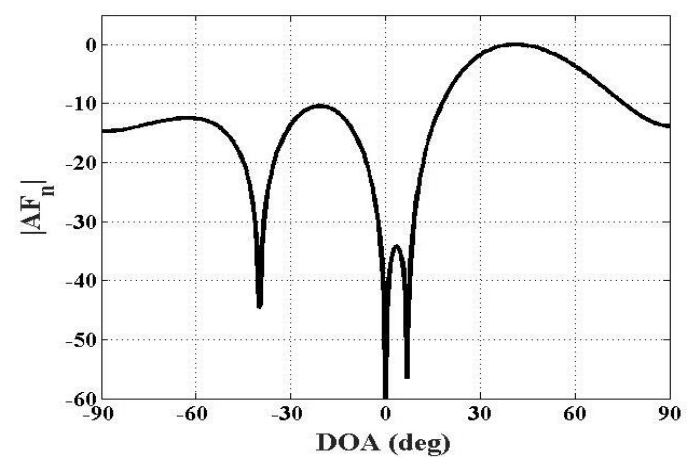

(b)

Figure 4. (a) max. Array o/p N=15, $\lambda=0.75$ and (b) max. SLL, main lobe for $\mathrm{N}=15, \lambda=0.75$

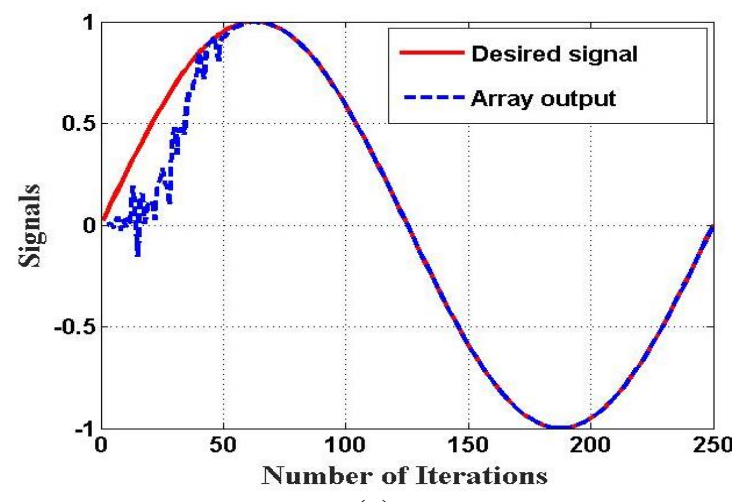

(a)

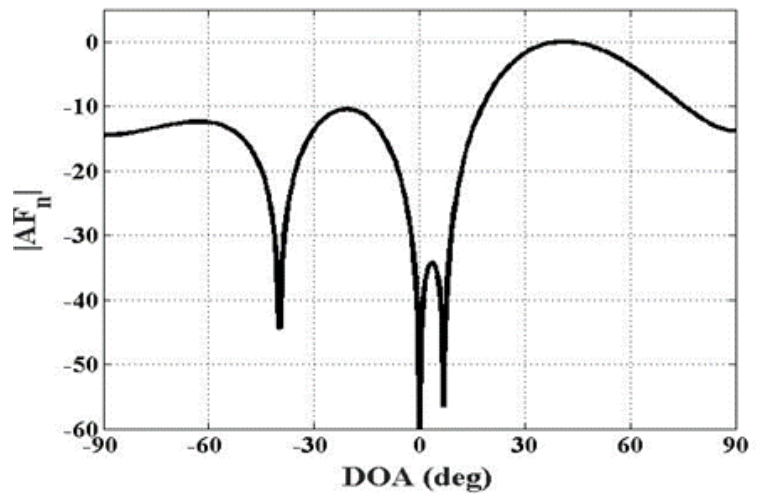

(b)

Figure 5. (a) max. Array o/p N=20, $\lambda=0.5$ and (b) max. SLL, main lobe for $\mathrm{N}=20, \lambda=0.5$

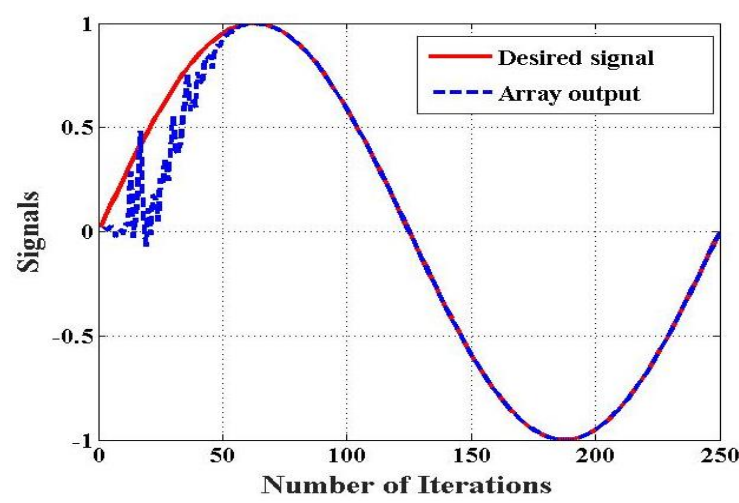

(a)

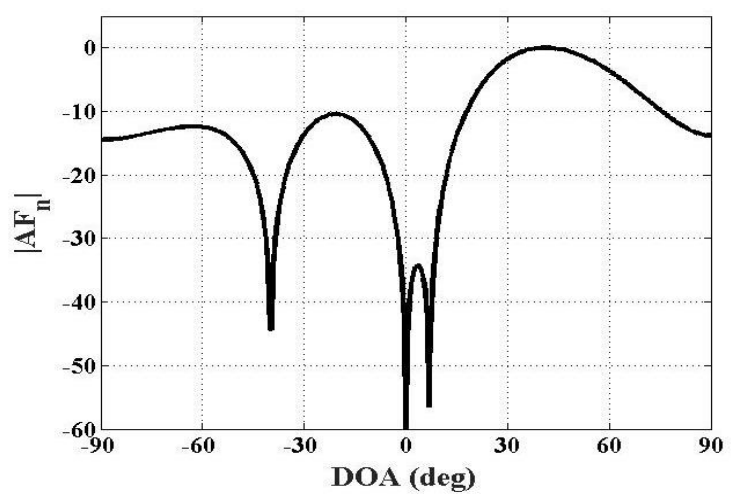

(b)

Figure 6. (a) max. Array o/p N=20, $\lambda=0.75$ and (b) max. SLL, main lobe for $\mathrm{N}=20, \lambda=0.75$

\section{CONCLUSION}

In this paper, a cultural algorithm was used to form the radiated beam of the circular antenna array, where the optimal beam pattern with minimum sidelobe level is achieved. In general, it can realize that the increasing number of elements in a UCAA results in a better beam pattern due to a narrower beam and more directivity. This enhancement occurs in the amplitude level and the sidelobe numbers, respectively. It is also observed that when the distance between elements is increased, this results in narrower beamwidth, thereby better directivity on the account of increased sidelobe level. The findings demonstrated that CA provides imposed raising in beamforming. 


\section{REFERENCES}

[1] A. S. Daghal, H. Zhu, and J. Wang, "Content Delivery Analysis in Multiple Devices to Single Device Communications," in IEEE Transactions on Vehicular Technology, vol. 67, no. 11, pp. 10218-10231, Nov. 2018, doi: 10.1109/TVT.2018.2865012.

[2] A. S. Daghal and Q. Z. Ahmed, "Video Content Delivery Using Multiple Devices to Single Device Communications," 2016 IEEE 83rd Vehicular Technology Conference (VTC Spring), 2016, pp. 1-5, doi: 10.1109/VTCSpring.2016.7504528.

[3] A. S. Daghal, H. Zhu, and J. Wang, "Performance Analysis of Mobile Content Delivery in Multiple Devices to Single Device Communication," GLOBECOM 2017 - 2017 IEEE Global Communications Conference, 2017, pp. 1-5, doi: 10.1109/GLOCOM.2017.8254839.

[4] A. S. Daghal, H. Zhu, Q. Z. Ahmed, and Y. Pan, "Outage Performance Analysis of Content Delivery in Multiple Devices to Single Device Communications," 2017 IEEE 85th Vehicular Technology Conference (VTC Spring), 2017, pp. 1-5, doi: 10.1109/VTCSpring.2017.8108401.

[5] A. F. Athab and A. S. Daghal, "IOT System to Limit Speed Rate by Using GPS and RF Devices," IOP Conference Series: Materials Science and Engineering. vol. 928. no. 3. IOP Publishing, 2020, doi: 10.1088/1757899x/928/2/022111.

[6] A. F. Athab, A. S. Daghal, and S. A. Abas, "Vehicle Speed Reduction Based on Authorized Speed Limits," IOP Conference Series: Materials Science and Engineering. vol. 928, no. 2. IOP Publishing, 2020, doi: 10.1088/1757899x/928/3/032077.

[7] A. Chunawale and S. Sirsikar, "Minimization of average energy consumption to prolong lifetime of Wireless Sensor Network," 2014 IEEE Global Conference on Wireless Computing \& Networking (GCWCN), 2014, pp. 244-248, doi: 10.1109/GCWCN.2014.7030887.

[8] G. Wang, N. Wang, T. Xie, and H. Wu, "Study on Energy Consumption Optimization Strategy for Data Transmission in Wireless Networks," 2017 IEEE International Symposium on Parallel and Distributed Processing with Applications and 2017 IEEE International Conference on Ubiquitous Computing and Communications (ISPA/IUCC), 2017, pp. 873-879, doi: 10.1109/ISPA/IUCC.2017.00133.

[9] Y. Zeng, S. Guo, G. Liu, P. Li, and Y. Yang, "Energy-efficient Device Activation, Rule Installation and Data Transmission in Software Defined DCNs," in IEEE Transactions on Cloud Computing, doi: 10.1109/TCC.2019.2947900.

[10] C.A. Balanis, Antenna Theory: Analysis and Design, 3rd ed., Wiley, New York, 2005.

[11] D. Chang and C. Hu, "Smart Antennas for Advanced Communication Systems," in Proceedings of the IEEE, vol. 100, no. 7, pp. 2233-2249, July 2012, doi: 10.1109/JPROC.2012.2187409.

[12] S, Bahri and F. Bendimerad. "Performance of adaptive beamforming algorithm for LMS-MCCDMA MIMO smart antennas," Int. Arab J. Inf. Technol, vol. 6, no. 3, July 2009, pp. 283-288.

[13] A. I. Mohsin, A. S. Daghal, and A. H. Sallomi, "A beamforming study of the linear antenna array using grey wolf optimization algorithm," Indonesian Journal of Electrical Engineering and Computer Science, vol. 20, no. 3, Dec. 2020, pp. 1538-1546, doi: 10.11591/ijeecs.v20.i3.pp1538-1546.

[14] A. D. M. Africa, R. R. M. Tagabuhin, and J. J. SD Tirados, "Design and simulation of an adaptive beam smart antenna using MATLAB," Indonesian Journal of Electrical Engineering and Computer Science, vol. 21, no. 3, March 2021, pp. 1584-1593, doi: 10.11591/ijeecs.v21.i3.pp. 1584-1593.

[15] N. A. Lafta, and S. S. Hreshee, "Wireless sensor network's localization based on multiple signal classification algorithm," International Journal of Electrical and Computer Engineering, vol. 11, no. 1, Feb. 2021, pp. 498-507, doi: 10.11591/ijece.v11i1.pp498-507.

[16] H. G. Hao, W. S. Hu, W. Ruan, and W. Chen, "Miniaturization smart antenna array design for TDSCDMA system," TELKOMNIKA Telecommunication, Computing, Electronics and Control, vol.12, no.2, pp. 1431-1437, 2014, doi: 10.11591/telkomnika. v12i2.3752.

[17] F. M. Amjad, A. Z. Sha'ameri, K. M. Yusof, and P. Eberechi, "Aircraft position estimation using angle of arrival of received radar signals," Bulletin of Electrical Engineering and Informatics, vol. 9, no. 6, Dec. 2020, pp. 2380-2387, doi: 10.11591/eei.v9i6.2273.

[18] T. G. Shivapanchakshari, and H. S. Aravinda. "PSO-CCO_MIMO-SA: A particle swarm optimization based channel capacity optimization for MIMO system incorporated with smart antenna." International Journal of Electrical and Computer Engineering (IJECE), vol. 10, no. 6, Dec. 2020, pp. 6276-6282, doi: 10.11591/ijece.v10i6.pp6276-6282.

[19] E. N. Umayah, and V. M. Srivastava, "Comparative analysis of feeding techniques for cylindrical surrounding patch antenna," International Journal of Electrical and Computer Engineering, vol. 10, no. 5, Oct. 2020, pp. 5377-5384, doi: 10.11591/ijece.v10i5.pp5377-5384.

[20] A. H. Ali, M. A. M. Al-Ja'afari, and S. H. Abdulwahed, "Performance assessment of antenna array for an unmanned air vehicle," International Journal of Electrical and Computer Engineering, vol. 10, no. 3, June 2020, pp. 2579-2588, doi: 10.11591/ijece.v10i3.pp2579-2588.

[21] M. Elhefnawy, "Design and simulation of an analog beamforming phased array antenna," International Journal of Electrical and Computer Engineering, vol. 10, no. 2, Apr. 2020, pp. 1398-1405, doi: 10.11591/ijece.v10i2.pp1398-1405.

[22] N. Mukit, et al., "Designing large-scale antenna array using sub-array," Bulletin of Electrical Engineering and Informatics, vol. 8, no. 3, Sept. 2019, pp. 906-915, doi: 10.11591/eei.v8i3.1529.

[23] B. Boustani, A. Baghdad, A. Sahel, and A. Badri, "Performance analysis of direction of arrival algorithms for smart antenna." International Journal of Electrical and Computer Engineering, vol. 9, no. 6, Dec. 2019, pp. 4873, doi: 10.11591/ijece.v9i6.pp4873-4881. 
[24] M. Haardt and Q. Spencer, "Smart antennas for wireless communications beyond the third generation", Elsevier, vol. 26, no. 1, pp. 41-45, Jan. 2003, doi: 10.1016/S1403-3664(02)00118-4.

[25] R. M. Shubair, M. A. Al-Qutayri and J. M. Samhan, "A Setup for the Evaluation of MUSIC and LMS Algorithms for a Smart Antenna System," J. Comm., vol. 2, no. 4, pp. 71-77, June 2007.

[26] A. I. Mohsin, A. S. Daghal, and A. H. Sallomi, "A beamforming comparative study of least mean square, genetic algorithm and grey wolf optimization algorithms for multipath smart antenna system," TELKOMNIKA, vol. 18, no. 6, Dec. 2020, pp. 2911-2920, doi: 10.12928/telkomnika.v18i6.16970.

[27] R. G. Reynolds, “An Introduction to Cultural Algorithms," Department of Computer Science 431 state Hall Wayne State University Detroit Michigan 48202.

[28] M. D. R. Ribeiro and M. S. d. Aguiar, "Cultural Algorithms: A Study of Concepts and Approaches," 2011 Workshop-School on Theoretical Computer Science, 2011, pp. 145-148, doi: 10.1109/WEIT.2011.24.

[29] H. C. Kuo and C. H. Lin, "Cultural evolution algorithm for global optimizations and its applications," Journal of applied research and technology, vol. 11, no. 4, Aug. 2013, pp. 510-522, doi: 10.1016/S1665-6423(13)71558-X.

[30] N. H. Awad, M. Z. Ali and R. M. Duwairi, "Cultural Algorithm with improved local search for optimization problems," 2013 IEEE Congress on Evolutionary Computation, 2013, pp. 284-291, doi: 10.1109/CEC.2013.6557582.

[31] R. G. Reynolds and L. Kinnaird-Heether, "Diversity as a Necessity for Sustainability in Cultural Systems: Collective Problem-Solving in Cultural Algorithms," 2019 IEEE International Conference on Humanized Computing and Communication (HCC), Laguna Hills, CA, USA, 2019, pp. 24-30, doi: 10.1109/HCC46620.2019.00012.

[32] T. de Amorim Monteiro, E. Q. de Albuquerque, and A. M. Balieiro, "Traffic Engineering in SDN with Cultural Algorithms," 2018 IEEE Latin American Conference on Computational Intelligence (LA-CCI), Gudalajara, Mexico, 2018, pp. 1-5, doi: 10.1109/LA-CCI.2018.8625225.

[33] V. S. S. S. C. Vedula, S. R. C. Paladuga, and M. R. Prithvi, "Synthesis of Circular Array Antenna for Sidelobe Level and Aperture Size Control Using Flower Pollination Algorithm," vol. 2015, Sept. 2015, doi: 10.1155/2015/819712

[34] H. Kollipara, "Design of a Uniform Circular Phased Array Smart Antenna for 2. 4 GHZ Applications," The University of Texas at TYLER, 2011.

[35] M. Khodier and M. A. Laqeel, "Linear and circular array optimization a study using particle swarm intelligence," Progress In Electromagnetics Research B, vol. 15, pp. 347-373, 2009.

[36] A. K. Y. Zamel and A. M. Abdulsattar, "Evaluation of Circular Array Antenna for Mobile Base Station to Increase Reverse-Link Capacity," AL-mansour Journal, vol. 17, pp. 19-36, 2012.

[37] C. Fajardo, M. Bataller, A. V. Nogueira, and J. A. Forero, "The effect of array spacing and the influence of the radiation pattern of the element in a pattern synthesis of uniform circular arrays," Ingeniería, vol. 8, no. 2, pp. 4-5, 2003, doi: 10.14483/23448393.2684.

[38] M. A. Ihedrane and S. Bri, "Direction of arrival using uniform circular array based on 2-D MUSIC algorithm," Indonesian Journal of Electrical Engineering and Computer Science (IJEECS), vol. 12, no. 1, Oct. 2018, pp. 30-37, doi: 10.11591/ijeecs.v12.i1.pp30-37.

[39] Y. M. Tabra and B. M. Sabbar, "Hybrid MVDR-LMS beamforming for massive MIMO." Indonesian Journal of Electrical Engineering and Computer Science, vol. 16, no. 2, Nov. 2019, pp. 715-723, doi: 10.11591/ijeecs.v16.i2.pp715-723.

[40] G. Gebrekrstos, G. T. Tesfamariam, and M. Ismail, "Performance evaluation of elliptical-cylindrical antenna array (EcAA) using SaDE optimized hyper beam," Indonesian Journal of Electrical Engineering and Computer Science, vol. 7, no. 1, July. 2017, pp. 178-188, doi: 10.11591/ijeecs.v7.i1.pp178-188.

[41] O. O. Adedayo, M. O. Onibonoje, and O. M. Adegoke, "Optimetric analysis of $1 \times 4$ array of circular microwave patch antennas for mammographic applications using adaptive gradient descent algorithm," International Journal of Electrical and Computer Engineering, vol. 9, no. 6, Dec. 2019, pp. 5159-5164, doi: 10.11591/ijece.v9i6.pp5159-5164.

[42] T. Firmansyah et al., "Bandwidth enhancement and miniaturization of circular-shaped microstrip antenna based on beleved half-cut structure for MIMO $2 \times 2$ application," International Journal of Electrical \& Computer Engineering, vol.9, no. 2, Apr. 2019, pp. 1110-1121, doi: 10.11591/ijece.v9i2.pp.1110-1121.

[43] N. H. M. Adnan, I. Md Rafiqul, and AHM Zahirul Alam, "Effects of Inter-Element Spacing and Number of Elements on Planar Array Antenna Characteristics," Indonesian Journal of Electrical Engineering and Computer Science (IJEECS), vol. 10, no. 1, Apr. 2018, pp. 230-240, doi: 10.11591/ijeecs.v10.i1.pp230-240. 